\title{
Delamination and First Ply Failure Study of Composite Conoidal Shells
}

\author{
Kaustav Bakshi and Dipankar Chakravorty
}

\begin{abstract}
Interlaminar and intralaminar failure modes of composite conoidal shells are investigated in this paper using finite element as the mathematical tool. One of the prerequisites for confidently applying the composite shells in practical civil engineering is to have a comprehensive idea about the shell behavior under different loading conditions. The static bending and free vibration responses of laminated composite conoidal shells are now well known as a good number of technical papers have been published by different researchers. But for these materials which are weak in transverse shear failure may initiate at any inner lamina or interface and may remain undetected and unattended. Such latent damages may progress gradually and lead to a sudden total ply failure. Due to fabrication problems or overloading, delamination defect may occur and remain hidden within the lamina. Hence it is imperative to have knowledge of the first ply failure load and the load at which delamination initiates. To explore this area, in this paper, a simply supported shell is considered loaded by concentrated load. Lamination and the load position are varied to investigate the first ply failure characteristics of the composite shell. Well accepted failure theories like maximum stress, Hoffman, Tsai-Wu and Tsai-Hill are used in the current formulation to obtain failure loads. While obtaining the failure loads, each lamina is considered to be under plane stress condition i.e. no transverse stresses are considered to act on any lamina. Comparison of failure loads obtained from both the failure modes are also presented to get the minimum failure load which will govern the shell design.
\end{abstract}

Keywords--- Conoidal Shell, Delamination, First Ply Failure, Finite Element Method, Laminated Composite

\section{INTRODUCTION}

S HELL structures are preferred in the industry to cover large column free open spaces as are found in airports, shopping malls, auditoriums and car parking lots.The doubly curved singly ruled conoidal shells are very popular in civil engineering industry.

Laminated composites were introduced in the second half of the last century in civil engineering shells fabrication. The researchers started working on different aspects of laminated

Kaustav Bakshi, Research Scholar, Civil Engineering Department, Jadavpur University, Kolkata, India.E-mail:bakshi.kaustav@gmail.com

Dipankar Chakravorty, Professor, Civil Engineering Department, Jadavpur University, Kolkata,India.E-mail:prof.dipankar@gmail.com

DOI: 10.9756/BIJIEMS.1658 composite shells. Researchers like Nayak and Bandyopadhyay [1, 2], Das and Chakravorty [3, 4, and 5] and Bakshi et al. [6] studied bending and vibration characteristics of graphiteepoxy conoidal, recently.

It is important to note that failure study of the laminated conoidal shell is needed for their confident application in the industry. A laminated shell may fail in two ways i.e. interlaminar or intralaminar failure. Bolotin [7] presented a detailed study on the origin, growth and stability of delamination in composite structures. Matthew and Anthony [8] proposed a delamination criterion. Krishnamurthy et al. $[9,10]$ reported delamination failure of cylindrical shells subjected to impact. Bending behavior of delaminated cylindrical shells was reported by Acharyya et al. [11] and Kumari and Chakravorty $[12,13]$. Natural vibration and mode shapes of delaminated cylindrical shells were reported by Acharyya et al. [11]. First ply failure of laminated plates and shells also reported by Reddy and Reddy [14], Kam and Jan [15], Kam et al. [16] Prusty et al. [17], Kumar and Srivastava [18]. Reddy and Reddy [14] reported linear and nonlinear first ply failure loads of composite plates. Experimental first ply failure loads of composite plates were reported by Kam and Jan [15] and Kam et al. [16]. Prusty et al. [17] reported first ply failure loads of laminated shell panels and first ply failure loads of stiffened plates were studied by Kumar and Srivastava [18].

It is noted from the literature that failure study of laminated conoidal shells is not reported by any researcher although the importance of this shell form in the industry is enormous. To fill the void in the literature, the present study intends to study interlaminar and intralaminar failures of composite conoidal shell.

\section{MATHEMATICAL FoRMULATION}

A doubly curved laminated composite conoidal shell (Figure 1) with radii of curvature ' $R_{y y}$ ' and ' $R_{x y}$ ' is considered in the present study. The thickness of the shell ' $h$ ' consists of a number of laminae in each of which, fibers may be arbitrarily oriented along the local axis of the lamina and at an angle ' $\theta$ ' with reference to the global $x$-axis of the shell (Figure 2). The governing equations of the composite shell, straindisplacement relations as well as the cubical shape functions adopted here are same as those were reported by Das and Chakravorty [3]. The static bending problem is solved by employing Gauss elimination method and the displacements are further used to evaluate the stress as explained below.

Lamina strains situated at a distance ' $z$ ' from the midplane are evaluated in global axes as, 


$$
\varepsilon_{x}=\varepsilon_{x}^{0}+z \kappa_{x}, \varepsilon_{y}=\varepsilon_{y}^{0}+z \kappa_{y} \text { and } \gamma_{x y}=\gamma_{x y}^{0}+z \kappa_{x y}
$$

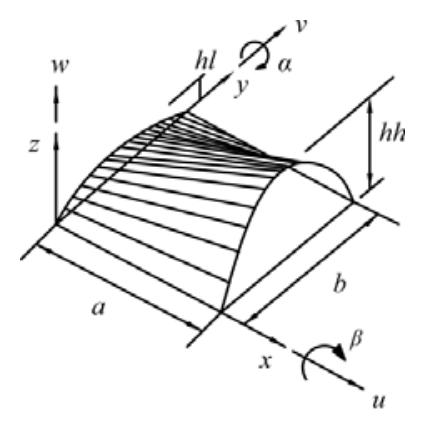

Figure 1: A Typical Conoidal Shell

Lamina strains are transformed from the global axes of the shell to the local axes of the lamina using transformation matrix,

$$
\left\{\begin{array}{c}
\varepsilon_{1} \\
\varepsilon_{2} \\
\frac{\varepsilon_{6}}{2}
\end{array}\right\}=\left[\begin{array}{ccc}
m^{2} & n^{2} & 2 m n \\
n^{2} & m^{2} & -2 m n \\
-m n & m n & m^{2}-n^{2}
\end{array}\right]\left\{\begin{array}{c}
\varepsilon_{x} \\
\varepsilon_{y} \\
\frac{\varepsilon_{x y}}{2}
\end{array}\right\}
$$

where $m=\sin \theta$ and $n=\cos \theta$.

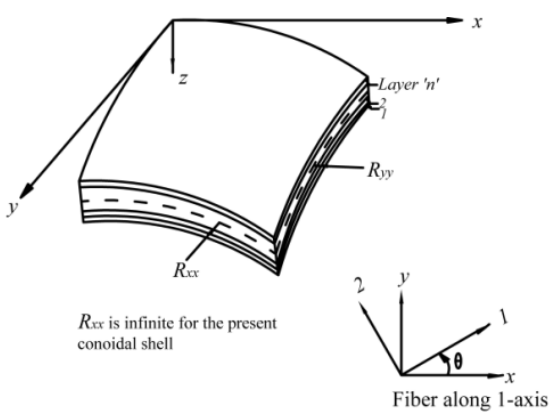

Figure 2: General Doubly Curved Laminated Composite Shell Element

Lamina stresses are obtained using the constitutive relation of the lamina,

$$
\left\{\begin{array}{l}
\sigma_{1} \\
\sigma_{2} \\
\sigma_{6}
\end{array}\right\}=\left[\begin{array}{ccc}
Q_{11} & Q_{12} & 0 \\
Q_{12} & Q_{22} & 0 \\
0 & 0 & Q_{66}
\end{array}\right]\left\{\begin{array}{l}
\varepsilon_{1} \\
\varepsilon_{2} \\
\varepsilon_{6}
\end{array}\right\}
$$

Where $Q_{12}=\left(1-v_{12} v_{21}\right)^{-1} E_{11} v_{21}, Q_{11}=\left(1-v_{12} v_{21}\right)^{-1} E_{11}$, $Q_{22}=\left(1-v_{12} v_{21}\right)^{-1} E_{22}, Q_{66}=G_{12}$.

Well known failure theories like maximum stress, Hoffman, Tsai-Wu and Tsai-Hill are used to obtain the intralaminar and interlaminar failure loads of the conoidal shell. The expressions of the failure theories used in the present study are those reported by Reddy and Reddy [14].

The lamina stresses, $\sigma_{2}$ and $\sigma_{6}$ are utilized to evaluate the delamination failure loads. These stresses correspond to two consecutive laminae are averaged to obtain their values at the interface and are further used in the aforementioned failure theories to get the delamination failure loads.

\section{NUMERICAL PROBLEMS}

A finite element code is developed for the present study which is used to obtain the failure loads of the composite conoidal shells. The bending formulation is validated by comparing the static displacements obtained from the present formulation with the values published by Hadid [19] [Refer Table 1].The failure formulation is validated by comparing the first ply loads of a partially clamped plate. The present results are compared with the values reported by Kam et al. [16] [Refer Table 2].

Several other numerical problems of simply supported composite conoidal shells are also studied .The Q-1115 graphite-epoxy is considered as fabrication material for the conoidal shells under study and the corresponding material properties are those as reported by Kam et al. [16]. The shell options under study are subjected to concentrated load at the centre. The failure loads, failure locations on the shell surface and the failed lamina, counted from the top of the laminate downwards, correspond to the first ply failure and delamination failure of the composite conoidal shells are reported in Tables 3 and 4 respectively.

\section{RESUlTS AND DisCUSSION}

Tables 1 and 2 shows good agreement between the present results and the benchmark values.

Table 1: Deflections of Isotropic Conoid under Uniformly Distributed Load along $\bar{y}=0.5$

\begin{tabular}{ccc}
\hline$x / L$ & $\begin{array}{c}\text { Deflections obtained by } \\
\text { Hadid [19] in 'mm' }\end{array}$ & $\begin{array}{c}\text { Deflections from present } \\
\text { formulation in 'mm' }\end{array}$ \\
\hline 0 & 0 & 0 \\
0.25 & -0.05081 & -0.05062 \\
0.5 & -0.00435 & -0.00363 \\
0.75 & -0.00290 & -0.00287 \\
1.0 & 0 & 0 \\
\hline
\end{tabular}

Table 2: Comparison Of First Ply Failure Loads In Newton

\begin{tabular}{cccc}
\multicolumn{3}{c}{ For a $\left(0_{2}^{0} / 90^{\circ}\right)_{\mathrm{s}}$ Plate } \\
\hline $\begin{array}{c}\text { Failure } \\
\text { criteria }\end{array}$ & $a / h$ & $\begin{array}{c}\text { First ply failure } \\
\text { loads } \\
\text { (Kam et al [16]) }\end{array}$ & $\begin{array}{c}\text { First ply failure } \\
\text { loads } \\
\text { (present } \\
\text { formulation) }\end{array}$ \\
\hline $\begin{array}{c}\text { Maximum } \\
\text { stress }\end{array}$ & 108.26 & 112.14 \\
$\begin{array}{c}\text { Hoffman } \\
\text { Tsai-Wu }\end{array}$ & 105.26 & 106.45 & 98.40 \\
Tsai-Hill & & 112.77 & 110.50 \\
\hline
\end{tabular}

Four well accepted failure theories are used in the present study to obtain the failure loads for a given lamination and the minimum failure load among them is designated as the first ply failure strength of that lamination. It is noted from Table 3 that the first ply failure loads of cross ply laminated shells are higher than the angle ply ones when the stacking orders are same. The simply supported conoidal shells deform along its two plan directions. In cross ply laminated shells, the fibers are running parallel to the plan directions while in angle ply ones, no fibers are running along the directions of deformations. As the elastic modulus of laminae along the 
fiber direction is higher compared to the perpendicular direction of the fibers, the cross ply laminated shells show higher first ply failure loads compared to the angle ply ones. In all the shell options, (except in the $45^{\circ} / 45^{0}$ shell where the failure load obtained from Hoffman failure theory overestimates the minimum failure load by 1.03 times only which is a nominal margin) Hoffman failure theory shows the least failure load and hence governs the design of the shell for first ply failure mode point of view. The bottommost lamina failed first for the shells under study and the failures are occur under the concentrated load. Higher stress concentration under the concentrated load leads to the tensile failure of the bottommost ply. The $0^{0} / 90^{\circ} / 0^{0}$ shell exhibits the highest first ply failure load and shows the best performance among all the stacking orders.

For delamination study the stresses are evaluated at the lamina interfaces and are used in the failure theories to obtain the delamination failure loads. The minimum failure load for a given lamination is designated as the delamination strength of the laminate. It is noted from Table 4 that the delamination strength is highest for the two layered cross ply shell. The two layered angle ply shell also shows the highest failure load when the comparisons of failure loads are restricted within angle ply laminates. In two layered shells, the top and the bottom laminae subjected to compressive and tensile stresses respectively and both laminae maintain the equilibrium of the shell. Moreover, for two layered shells the plane prone to delamination is only one. Therefore the lamina interfaces in these shells subjected to negligible stresses compared to the three and four layered shells. This is why the lamina interfaces in two layered shells fail in significant higher loads compared to lamina interfaces in three layered and four layered shells. Hoffman failure theory governs the delamination failure load for all the cross ply shells while for the angle ply shells, Tsai$\mathrm{Wu}$ failure theory shows the minimum delamination failure load.

Table 3 and 4 shows that for two and three layered cross ply shells the first ply failure mode governs the design of the shell as the failure loads are lower compared to the corresponding delamination failure loads. However for the four layered cross ply shell with antisymmetric stacking order, the delamination failure load governs. This is true for symmetric $0^{0} / 90^{\circ} / 90^{\circ} / 0^{0}$ shell also but for this the delamination and first ply failure loads give close results. It is further observed that for all angle ply shells, delamination failure loads are more than the first ply failure loads for all the stacking orders under study. The observation clearly indicates that detailed study is required to actually predict the failure load of a laminated composite conoidal shell roof.

Table 3: First Ply Failure Loads of the Simply Supported Composite Conoidal Shells

\begin{tabular}{|c|c|c|c|c|}
\hline $\begin{array}{l}\text { Lamination } \\
\text { (degree) }\end{array}$ & Failure theory & $\begin{array}{l}\text { First ply failure load } \\
\text { (Newton) }\end{array}$ & $\begin{array}{l}\text { Failure location }(\mathrm{m}, \mathrm{m}) \\
(x, y)\end{array}$ & $\begin{array}{c}\text { Failed ply from top of } \\
\text { the laminate }\end{array}$ \\
\hline \multirow{4}{*}{$0 / 90$} & Maximum stress & 30399 & $(4,4)$ & 2 \\
\hline & Hoffman & $20244^{\mathrm{L}}$ & $(4,4)$ & 2 \\
\hline & Tsai-Hill & 22901 & $(4,4)$ & 2 \\
\hline & Tsai-Wu & 22963 & $(4,4)$ & 2 \\
\hline \multirow{4}{*}{$0 / 90 / 0$} & Maximum stress & 23820 & $(4,4)$ & 3 \\
\hline & Hoffman & $20899^{\mathrm{L}}$ & $(4,4)$ & 3 \\
\hline & Tsai-Hill & 22168 & $(4,4)$ & 3 \\
\hline & Tsai-Wu & 23461 & $(4,4)$ & 3 \\
\hline \multirow{4}{*}{ 0/90/0/90 } & Maximum stress & 22697 & $(4,4)$ & 4 \\
\hline & Hoffman & $19744^{\mathrm{L}}$ & $(4,4)$ & 4 \\
\hline & Tsai-Hill & 21000 & $(4,4)$ & 4 \\
\hline & Tsai-Wu & 22225 & $(4,4)$ & 4 \\
\hline \multirow{4}{*}{ 0/90/90/0 } & Maximum stress & 22234 & $(4,4)$ & 4 \\
\hline & Hoffman & $20000^{\mathrm{L}}$ & $(4,4)$ & 4 \\
\hline & Tsai-Hill & 21036 & $(4,4)$ & 4 \\
\hline & Tsai-Wu & 22241 & $(4,4)$ & 4 \\
\hline \multirow{4}{*}{$45 /-45$} & Maximum stress & 7192 & $(4,4)$ & 2 \\
\hline & Hoffman & 7187 & $(4,4)$ & 2 \\
\hline & Tsai-Hill & 7152 & $(4,4)$ & 2 \\
\hline & Tsai-Wu & $6939^{\mathrm{L}}$ & $(4,4)$ & 2 \\
\hline \multirow{4}{*}{$45 /-45 / 45$} & Maximum stress & 13283 & $(4,4)$ & 3 \\
\hline & Hoffman & $13197^{\mathrm{L}}$ & $(4,4)$ & 3 \\
\hline & Tsai-Hill & 13269 & $(4,4)$ & 3 \\
\hline & Tsai-Wu & 13450 & $(4,4)$ & 3 \\
\hline \multirow{4}{*}{$45 /-45 / 45 /-45$} & Maximum stress & 12946 & $(4,4)$ & 4 \\
\hline & Hoffman & $12876^{\mathrm{L}}$ & $(4,4)$ & 4 \\
\hline & Tsai-Hill & 12936 & $(4,4)$ & 4 \\
\hline & Tsai-Wu & 13090 & $(4,4)$ & 4 \\
\hline \multirow{3}{*}{$45 /-45 /-45 / 45$} & Maximum stress & 13002 & $(4,4)$ & 4 \\
\hline & Hoffman & $12894^{\mathrm{L}}$ & $(4,4)$ & 4 \\
\hline & Tsai-Hill & 12981 & $(4,4)$ & 4 \\
\hline
\end{tabular}


Note: ${ }^{\mathrm{L}}$ Indicates first ply failure load of the laminate, $a=b=800 \mathrm{~mm}, h=8 \mathrm{~mm}, h h=160 \mathrm{~mm}, h l=40 \mathrm{~mm}$

Table 4: Delamination Failure Loads of the Simply Supported Composite Conoidal Shells

\begin{tabular}{|c|c|c|c|c|}
\hline Lamination (degree) & Failure theory & $\begin{array}{c}\text { Delamination failure } \\
\text { load } \\
\text { (Newton) }\end{array}$ & $\begin{array}{l}\text { Failure location }(\mathrm{m}, \mathrm{m}) \\
(x, y)\end{array}$ & $\begin{array}{l}\text { Failed interface from } \\
\text { top of the laminate }\end{array}$ \\
\hline \multirow{4}{*}{$0 / 90$} & Maximum stress & 153748 & $(3.04,3.0)$ & 1 \\
\hline & Hoffman & $117850^{\mathrm{L}}$ & $(5.04,4.0)$ & 1 \\
\hline & Tsai-Hill & 153250 & $(3.04,3.0)$ & 1 \\
\hline & Tsai-Wu & 117852 & $(5.04,4.0)$ & 1 \\
\hline \multirow{4}{*}{ 0/90/0 } & Maximum stress & 62312 & $(4,4)$ & 2 \\
\hline & Hoffman & $36295^{\mathrm{L}}$ & $(4,4)$ & 2 \\
\hline & Tsai-Hill & 62312 & $(4,4)$ & 2 \\
\hline & Tsai-Wu & 36300 & $(4,4)$ & 2 \\
\hline \multirow{4}{*}{ 0/90/0/90 } & Maximum stress & 28190 & $(4,4)$ & 3 \\
\hline & Hoffman & $16420^{\mathrm{L}}$ & $(4,4)$ & 3 \\
\hline & Tsai-Hill & 28190 & $(4,4)$ & 3 \\
\hline & Tsai-Wu & 16422 & $(4,4)$ & 3 \\
\hline \multirow{4}{*}{ 0/90/90/0 } & Maximum stress & 32615 & $(4,4)$ & 3 \\
\hline & Hoffman & $19000^{\mathrm{L}}$ & $(4,4)$ & 3 \\
\hline & Tsai-Hill & 32615 & $(4,4)$ & 3 \\
\hline & Tsai-Wu & 19002 & $(4,4)$ & 3 \\
\hline \multirow{4}{*}{$45 /-45$} & Maximum stress & 55225 & $(3.04,5.0)$ & 1 \\
\hline & Hoffman & 32186 & $(3.04,5.0)$ & 1 \\
\hline & Tsai-Hill & 55225 & $(3.04,5.0)$ & 1 \\
\hline & Tsai-Wu & $32185^{\mathrm{L}}$ & $(3.04,5.0)$ & 1 \\
\hline \multirow{4}{*}{$45 /-45 / 45$} & Maximum stress & 31749 & $(4,4)$ & 2 \\
\hline & Hoffman & 18500 & $(4,4)$ & 2 \\
\hline & Tsai-Hill & 31740 & $(4,4)$ & 2 \\
\hline & Tsai-Wu & $18489^{\mathrm{L}}$ & $(4,4)$ & 2 \\
\hline \multirow{4}{*}{$45 /-45 / 45 /-45$} & Maximum stress & 30162 & $(4,4)$ & 3 \\
\hline & Hoffman & 17570 & $(4,4)$ & 3 \\
\hline & Tsai-Hill & 30158 & $(4,4)$ & 3 \\
\hline & Tsai-Wu & $17568^{\mathrm{L}}$ & $(4,4)$ & 3 \\
\hline \multirow{4}{*}{$45 /-45 /-45 / 45$} & Maximum stress & 24878 & $(4,4)$ & 3 \\
\hline & Hoffman & 14490 & $(4,4)$ & 3 \\
\hline & Tsai-Hill & 24875 & $(4,4)$ & 3 \\
\hline & Tsai-Wu & $14490^{\mathrm{L}}$ & $(4,4)$ & 3 \\
\hline
\end{tabular}

Note: ${ }^{\mathrm{L}}$ Indicates first ply failure load of the laminate, $a=b=800 \mathrm{~mm}, h=8 \mathrm{~mm}, h h=160 \mathrm{~mm}, h l=40 \mathrm{~mm}$

Among the different stacking sequences considered in the present study the $0^{0} / 90^{\circ} / 0^{0}$ and $0^{\circ} / 90^{\circ}$ laminates show the maximum resistance against the first ply and delamination failures respectively and are taken up for further study with eccentric load positions. The load position is varied discretely along both the plan dimensions and also along the diagonal as furnished in Figures 3 to 8. Interestingly for both first ply and delamination failures the failure load value does not show any unified correlation with the load position, rather the failure load varies harmonically with change in load position eccentrically. One common trend which are found for both first ply and delamination failure modes is that the absolute maximum value of the failure load are achieved for a load position eccentric along the beam direction. The absolute maximum value for the first ply failure load is almost 2.5 times of the failure load when the load is concentric. For delamination failure mode the absolute maximum value of the failure load is about 1.4 times of what one gets when the load is concentric. Another behavior for eccentric load positions which is somewhat unified is the fact that shifting the load position along the diagonal does not change the failure loads to any appreciable extent but when $e_{d} / d$ exceeds ' $1 / 4$ 'the failure load value shows a sharp abrupt decrease in its magnitude. These observations lead to the conclusion that a bit of load eccentricity along the diagonal may be allowed any loss of ultimate stiffness but if the load have to be placed along one of the plan directions only, then a detailed analysis has to be done before taking a decision. 


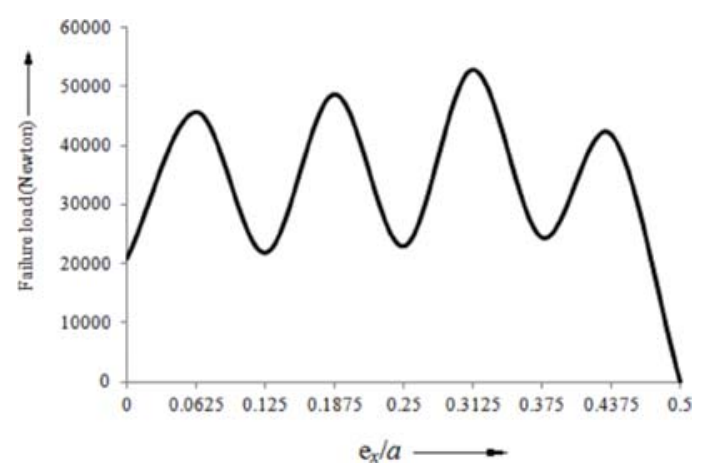

Figure 3: Variation of First Ply Failure Load of $0^{0} / 90^{\circ} / 0^{0}$ Shell with Eccentricity of Load in $X$ Direction

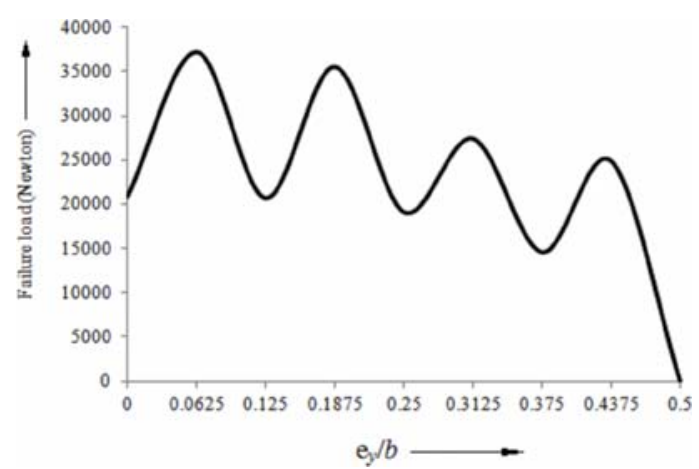

Figure 4: Variation of First Ply Failure Load of $0^{0} / 90^{\circ} / 0^{0}$ Shell with Eccentricity of Load in $Y$ Direction

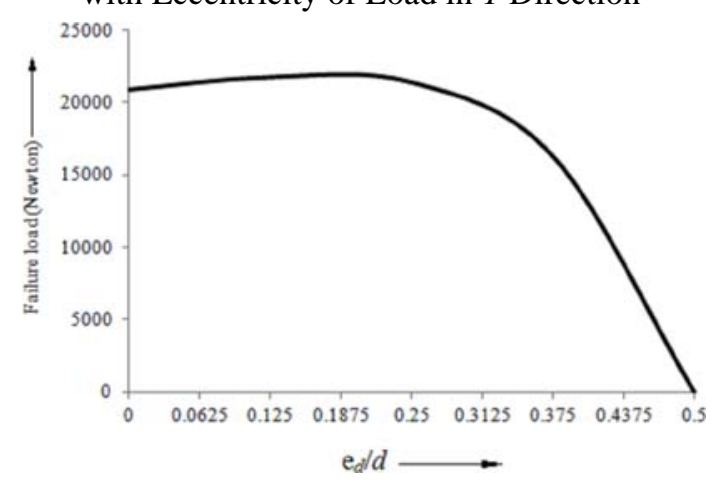

Figure 5: Variation of First Ply Failure Load of $0^{0} / 90^{\circ} / 0^{0}$ Shell with Eccentricity of Load in Diagonal Direction

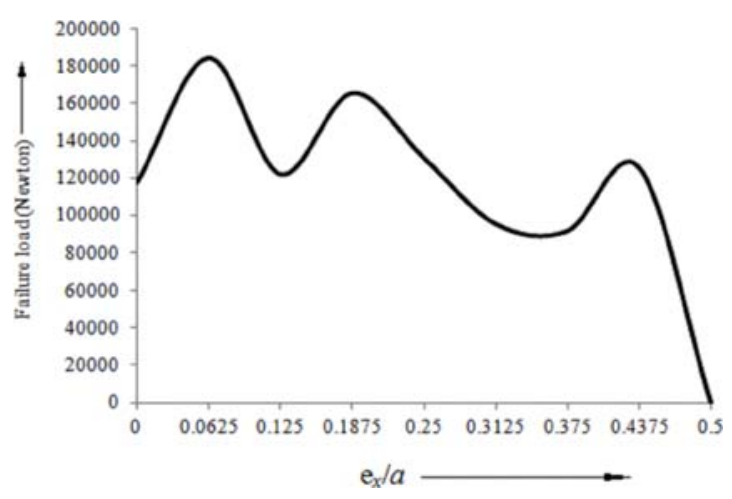

Figure 6: Variation of Delamination Failure Load of $0^{\circ} / 90^{\circ}$ Shell with Eccentricity of Load in $X$ Direction

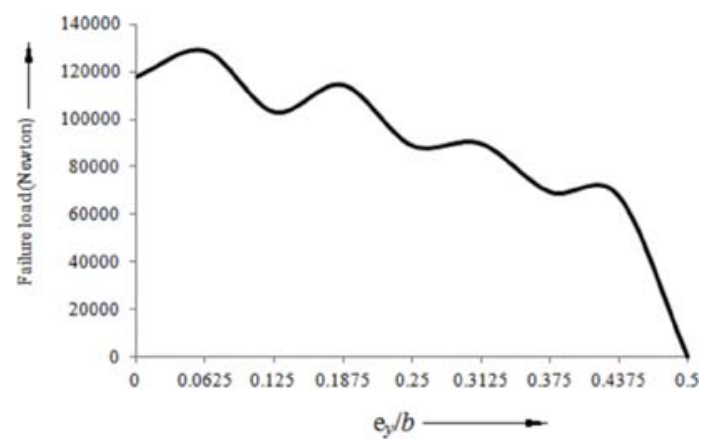

Figure 7: Variation of Delamination Failure Load of $0^{0} / 90^{\circ}$ Shell with Eccentricity of Load in $Y$ Direction

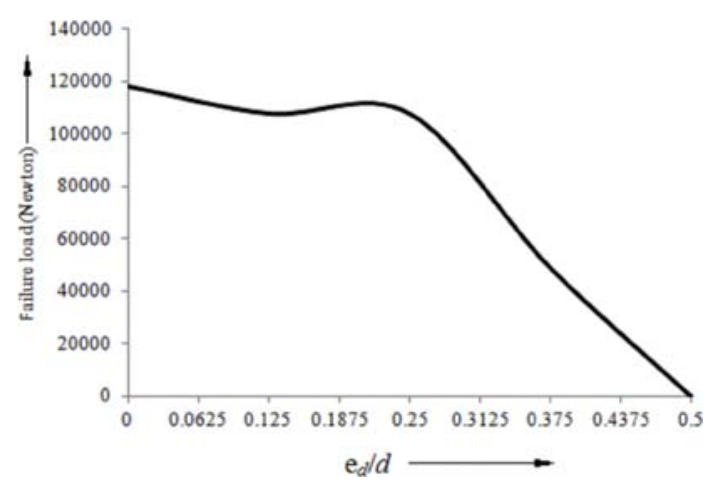

Figure 8: Variation of Delamination Failure Load of $0^{\circ} / 90^{\circ}$ Shell with Eccentricity of Load in Diagonal Direction 


\section{CONCLUSION}

A finite element code is developed to study intralaminar and interlaminar failures of simply supported composite conoidal shells and validated through solution of benchmark problems. The comparative study of the failure loads for delamination and first ply failure modes show that a conoidal shell may fail either in delamination or in first ply failure mode depending on stacking sequence. Hence a comprehensive study is needed to estimate the actual failure load. This is actually the essence of this paper also. It may further be concluded that a bit of load eccentricity along the diagonal may be allowed without any appreciable loss of load carrying capacity but if the load has to be placed along one of the plan directions only, then a detailed analysis is to be done before taking a decision because such eccentric load position may result in substantial loss of structural stiffness.

\section{NOTATIONS}

\begin{tabular}{|c|c|}
\hline$a, b$ & Length and width of the shell. \\
\hline$E_{11}, E_{22,} E_{33}$ & Elastic moduli. \\
\hline$e_{x}, e_{y}, e_{d}$ & $\begin{array}{l}\text { Eccentricity of load measured from the center } \\
\text { of the shell along } x, y \text { and diagonal directions } \\
\text { respectively }\end{array}$ \\
\hline$G_{12}, G_{23}, G_{13}$ & Shear moduli. \\
\hline$h$ & Thickness of the shell. \\
\hline$h h, h l$ & Higher and lower height of the conoidal shell. \\
\hline$R_{y y}$ & $\begin{array}{l}\text { Radius of curvature of the conoidal shell } \\
\text { along } y \text { direction. }\end{array}$ \\
\hline$R_{x y}$ & $\begin{array}{l}\text { Radius of cross curvature of the conoidal } \\
\text { shell. }\end{array}$ \\
\hline$x, y$ and $z$ & Global co-ordinates of the laminate. \\
\hline $\bar{y}$ & Nondimensional form of $y$ coordinate $=y / b$. \\
\hline$\varepsilon_{x,} \varepsilon_{y}$ & $\begin{array}{l}\text { Inplane normal strains along } x \text { and } y \text { axes } \\
\text { respectively. }\end{array}$ \\
\hline$\varepsilon_{1,}, \varepsilon_{2}$ & $\begin{array}{l}\text { Inplane normal strains along } 1 \text { and } 2 \text { axes of a } \\
\text { lamina respectively. }\end{array}$ \\
\hline$\varepsilon_{6}$ & Inplane shear strain in 1-2 plane of a lamina. \\
\hline$\gamma_{x y}$ & Inplane shear strain in $x-y$ plane. \\
\hline$v_{\mathrm{ij}}$ & Poisson’s ratio. \\
\hline$\sigma_{1}, \sigma_{2}$ and $\sigma_{6}$ & Inplane lamina stresses. \\
\hline & Inplane shear stress in $x-y$ plane. \\
\hline$\kappa_{x}, \kappa_{y}, \kappa_{x y}$ & Curvatures of the shell due to load. \\
\hline
\end{tabular}

\section{ACKNOWLEDGMENT}

The first author gratefully acknowledges the financial assistance of Council of Scientific and Industrial Research (India) through the Senior Research Fellowship vide Grant no. 09/096 (0686) 2k11-EMR-I.

\section{REFERENCES}

[1] A. N. Nayak and J. N. Bandyopadhyay, "Free vibration analysis and design aids of stiffened conoidal shells." Journal of Engineering Mechanics, ASCE, Vol. 128, No. 4, Pp. 419-427, 2002.

[2] A. N. Nayak and J. N. Bandyopadhyay, "Dynamic response analysis of stiffened conoidal shells.” Journal of Sound and Vibration, Vol. 291, Pp. 1288-1297, 2006.

[3] H.S. Das and D. Chakravorty, "Design aids and selection guidelines for composite conoidal shell roofs - A finite element application.” Journal of Reinforced Plastics and Composites, Vol. 26, No. 17, Pp.1793-1819, 2007.

[4] H.S. Das and D. Chakravorty, "Finite element application in analysis and design of point supported composite conoidal shell roofs suggesting selection guidelines." The Journal of Strain Analysis for Engineering Design, Vol. 45, No. 3, Pp.165-177, 2010.

[5] H.S. Das and D. Chakravorty, "Bending analysis of stiffened composite conoidal shell roofs through finite element application.” Journal of Composite Materials, Vol. 45, No. 5, Pp.525-542, 2011.

[6] K. Bakshi, H.S. Das and D. Chakravorty, "Forced motions of composite conoidal shell roofs with complicated boundary conditions." Advanced Materials Research, Vol. 123-125, 2010.

[7] V. V. Bolotin, "Delaminations in composite structures: its origin, buckling, growth and stability.” Composites: Part B., Vol. 27B, Pp.129145, 1996.

[8] T.F. Matthew and J.V. Anthony, "The inclusion of in-plane stresses in delamination criteria.” Journal of Composite Materials, Vol. 35, No. 15, Pp.1325-1342, 2001.

[9] K.S. Krishnamurthy, P. Mahajan, and R.K. Mittal, “A parametric study of the impact response and damage of laminated cylindrical composite shells.” Composites Science and Technology, Vol. 61, Pp.1655-1669, 2001.

[10] K.S. Krishnamurthy, P. Mahajan, and R.K. Mittal, "Impact response and damage in laminated composite cylindrical shells." Composite Structures, Vol. 59, Pp.15-36, 2003.

[11] A. Acharyya, D. Chakravorty and A. Karmakar, "Bending characteristics of delaminated composite cylindrical shells - A finite element approach.” Journal of reinforced Plastic and Composites, Vol. 28, Pp.965-978, 2009.

[12] S. Kumari and D. Chakravorty, "On the bending characteristics of damaged composite conoidal shells - a finite element approach.” Journal of Reinforced Plastics and Composites, Vol. 29, No. 21, Pp.3287-3296, 2010.

[13] S. Kumari and D. Chakravorty, "Bending of delaminated composite conoidal shells under uniformly distributed load." Journal of Engineering Mechanics, ASCE, Vol. 137, No. 10, Pp.660-668, 2011.

[14] Y.S.N. Reddy and J.N. Reddy, "Linear and nonlinear failure analysis of composite laminates with transverse shear." Composites Science and Technology, Vol. 44, Pp.227-255, 1992.

[15] T.Y. Kam and T.B. Jan, "First ply failure analysis of laminated composite plates based on the layerwise linear displacement theory." Composite Structures, Vol. 32, Pp.583-591, 1995.

[16] T.Y. Kam, H.F. Sher, T.M. Chao and R.R. Chang, "Predictions of deflection and first ply failure load of thin laminated composite plates via the finite element approach.” International Journal of Solids and Structures, Vol. 33, Pp.375-398, 1996.

[17] B.G. Prusty, C. Ray and S.K. Satsangi, "First ply failure analysis of stiffened panels-a finite element approach." Composite Structures, Vol. 51, Pp.73-81, 2001.

[18] Y.V.S. Kumar and A. Srivastava, "First ply failure analysis of laminated stiffened plates.” Composite Structures, Vol. 60, Pp.307-315, 2003.

[19] H. A. Hadid, "An analytical and experimental investigation into the bending theory of elastic conoidal shells." Doctoral Dissertation, University of Southampton, 1964. 